\title{
New species of Eupsilocephala Kröber from Australia (Diptera: Therevidae)
}

\author{
SHAUN L. WINTERTON \\ California Department of Food \& Agriculture, California State Collection of Arthropods, Sacramento, Cali-
} fornia, USA.E-mail: swinterton@cdfa.ca.gov

\begin{abstract}
The stiletto fly genus Eupsilocephala Kröber is a member of the Taenogera genus-group endemic to Australia. Two new species of this rarely collected genus, Eupsilocephala albodorsalis $\mathbf{s p .}$ nov. and Eupsilocephala sulphurea sp. nov., are described.
\end{abstract}

Keywords: Eupsilocephala, Therevidae, Australia, taxonomy

\section{Introduction}

The Taenogera genus-group of stiletto flies (Diptera: Therevidae) presently comprise at least 13 described genera distributed throughout Australasia and parts of South America. This genus group is recognisable from other therevids by an open wing cell $\mathrm{m}_{3}$, femoral vestiture sparse and only of only a single type (i.e. macrosetae, scale-like setae and velutum patches lacking), inner gonocoxal process present and the female reproductive system with three spermathecae and a spermathecal sac (Winterton et al. 1999a-c, Winterton et al. 2001). Characters supporting monophyly of the Taenogera genus-group have proven elusive in all quantitative analyses (Winterton et al. 1999b, 2001, Yang et al. 1999) and the group appears to represent a paraphyletic assemblage closely related to the subfamily Agapophytinae. Stabilisation of the higher therevid classification given this paraphyly will likely involve expansion of the current definition of Agapophytinae to include these genera; a putative synapomorphy being the presence of three spermathecae joining to the spermathecal sac to form a common duct (see Winterton et al. 1999c). Australasian Taenogera genus-group genera include Actenomeros Winterton \& Irwin, Ectinorhynchus Macquart, Eupsilocephala Kröber, Johnmannia Irwin \& Lyneborg, Manestella Metz, Nanexila Winterton \& Irwin, Neodialineura Mann, Squamopygia 

Metz et al. 2003). The South American genera, found mostly in Argentina and Chile, are Melanothereva Malloch, Entesia Oldroyd and Pachyrrhiza Philippi. There are additional undescribed genera in New Caledonia, Fiji, Chile, and Australia that are presently awaiting description.

Members of the genus Eupsilocephala are typically characterised by dark, metallic colouration starkly contrasted with bright orange wings (Fig. 1). This genus has long been recognised as sister to the endemic Australian genus Johnmannia (Paramonov 1950, Winterton 1999b, Lambkin et al. 2005). Species of Eupsilocephala and Johnmannia are large, robust stiletto flies with a rounded body shape. Eupsilocephala presently has two described species: Eupsilocephala singula (Walker) from Western Australia and Eupsilocephala kroeberi Paramonov from Queensland and New South Wales. Both genera have only rarely been collected previously (Lambkin et al. 2005).

Walker (1848) originally described E. singula in Thereva Latreille from females collected in Western Australia, for which Kröber (1912) subsequently erected the genus Eupsilocephala for this highly distinctive species. Mann (1928) incorrectly redescribed Eupsilocephala and E. singula, based on a female specimen of the then undescribed Johnmannia tasmanica Paramonov from Tasmania (Paramonov 1950). This was an obvious oversight considering that Walker's original description, which was also quoted verbatim by Kröber (1912), clearly conflicts with the redescription by Mann (1928) even though he referred to it. Mann (1928: 158) also accused Kröber of not examining the type specimens of E. singula, but obviously from his redescription, this was something he himself was guilty of as well. Although Mann recognised this error in a subsequent publication (Mann 1933: 336-337), he compounded it in his 'corrected' redescription of E. singula by basing this redescription on specimens of the then undescribed E. kroeberi. Since his description matches E. kroeberi and not E. singula, it is obvious that he again did not examine the holotype. Moreover, he incorrectly designated a 'male' specimen of E. kroeberi from Queensland (deposited in the Queensland Museum) as the allotype for E. singula; this specimen (MEI 29145) is actually a female. Like previous workers, Paramonov (1950) also quoted Walker's original description of E. singula in his relatively detailed treatment of Eupsilocephala, and correctly associates three female specimens from Western Australia that closely match the original description. He also described E. kroeberi from two female specimens collected in Eidsvold, Queensland.

Mann (1928) considered Eupsilocephala to be closely allied to Anabarhynchus Macquart. Although they may be superficially similar, the two are not closely related. Rather, Anabarhynchus is a member of Therevinae, closely related to the New Zealand genus Megathereva Lyneborg, while Eupsilocephala is not a therevine, but is closely related to Johnmannia in the Taenogera genus-group (Winterton et al. 1999b). As pointed out by Lyneborg $(1992,2001)$, Eupsilocephala is also one of the few Australian genera (besides most notably Johnmannia and Anabarhynchus) with a small patch of setae on the 
metanepisternum ("hypopleural pile", sensu Lyneborg 1992).

This paper is another in a series describing the diverse and species-rich Australasian Therevidae fauna. Two new species of Eupsilocephala are described and figured herein from south-eastern Queensland. Eupsilocephala albodorsalis sp. nov. is described from both males and females while Eupsilocephala sulphurea sp. nov. is known from only a single female specimen. Males of Eupsilocephala are relatively rare, and are known in collections only for E. kroeberi and E. albodorsalis. Species of Eupsilocephala are distinctive based on external characters and can be separated using the key below.

\section{Revised key to Eupsilocephala species}

1. Body colouration dark yellow-orange; Queensland sulphurea sp. nov.

-. Body colouration metallic, dark blue-purple-orange reflections 2.

2. Scutal macrosetae and postocular setae orange; Queensland, New South Wales kroeberi Paramonov

-. Scutal macrosetae and postocular setae black 3.

3. Scutum glossy black with partial white stripes anteriorly; wing orange in basal half, dark infuscate in distal half; Western Australia singula (Walker)

-. Scutum densely covered with matte white pubescence; wing almost completely orange, dark at very base of wing; Queensland albodorsalis sp. nov.

\section{Materials and methods}

Terminology for wing venation follows McAlpine et al. (1981) and Irwin \& Lyneborg (1981) and genitalic morphology (including external genitalia and subterminal segments) as modified by Winterton et al. (1999a, b). Hauser \& Irwin (2003) provide a convincing argument for the use of the term pubescence sensu Nichols (1989) instead of pruinescence (rather than as proposed by Winterton et al. (1999a)) to describe microtrichia covering the adult body. Matte black or variously coloured pruinescence discussed by Winterton et al. (1999a) are hereafter described as matte black, or variously coloured pubescence. The term velutum is retained to describe a particular type of very densely packed, reflective (i.e. velvet-like) pubescence typically found on the male abdomen or on the femora of agapophytine therevids. It is hoped that this will result in greater uniformity in descriptive terminology of therevid vestiture used by workers on this group. Due to the enormous variation in shape, size and position of the non-articulated gonocoxal processes on the male gonocoxite (referred to as outer gonocoxal process, and ventral gonocoxal process by some authors), only the term gonocoxal process is used hereafter for these extensions of the gonocoxite. No homology is implied for these processes. Inner gonocoxal process is retained to describe the articulated process immediately laterad of the gonostylus. 
Genitalia were macerated in $10 \% \mathrm{KOH}$ at room temperature for one day to remove soft tissue, then rinsed in distilled water and dilute glacial acetic acid, and dissected in $80 \%$ ethanol. Female reproductive organs were stained with a saturated solution of Chlorazol Black in $40 \%$ ethanol. Genitalia preparations were placed in glycerine in a genitalia vial mounted on the pin beneath the specimen.

Types are deposited in the Queensland Museum (QMBA) and University of Queensland insect collections (UQIC) in Brisbane, and the Australian National Insect Collection (ANIC) in Canberra, Australia. Numbers quoted with individual specimens as MEI \#\#\#\#\# are unique identifiers in the therevid database MANDALA and are attached to each specimen as a yellow label (Kampmeier et al. 2004).

\section{Taxonomy}

Eupsilocephala albodorsalis sp. nov. (Figures 1-2)

Holotype male, AUSTRALIA: QUEENSLAND: Brisbane, Slaughter Falls, base of Mt.

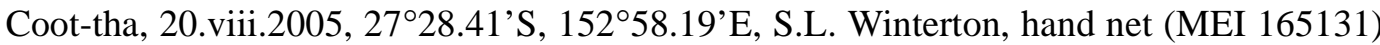
(QMBA).

Paratypes, AUSTRALIA: QUEENSLAND: male, same data as holotype (MEI 165132) (ANIC); female, Glen Aplin, 26.x.1963, P. Kerridge (MEI 129824) (UQIC).

\section{Diagnosis}

Body glossy black with metallic reflections; frons and gena orange; scutum densely overlain with matte, white-grey pubescence; head and scutal macrosetae black.

\section{Description}

Male: Body length: $7.0 \mathrm{~mm}$.

Head. Frons flat or slightly concave medially, width much narrower than ocellar tubercle at narrowest point, eyes almost contiguous just below ocellar tubercle; antenna positioned low on frons; frons and face pale orange, overlain with silver pubescence; eye ommatidia uniform size throughout eye; ocellar tubercle raised, black, overlain with sparse, grey pubescence admixed with several dark setae; occiput concave, dark medially, orange laterally, overlain with dense silver and black pubescence, single row of black postocular setae dorsally; gena orange, overlain with silver-white pubescence admixed with elongate black setae; palp and labellum orange, covered with dark setae; antenna bright orange, overlain with sparse grey pubescence, antennal length shorter than head, scattered, dark setae on scape and pedicel, flagellum with two apical segments and terminal style, style dark.

Thorax. Uniform glossy brown-black, scutum densely overlain with matte white-grey pubescence, admixed with short dark setae, scutal macrosetae black; matte white-grey 
pubescence absent on postalar callus, posteromedially between dorsocentral setae and as

two glabrous spots on transverse suture; scutellum glossy black; pleuron with dark, elongate setae on proepisternum, anepisternum, katepisternum, katatergite and small patch on metanepisternum; sparse grey pubescence on meron, metanepisternum and posterior margin of katepisternum; coxae glossy dark-brown, overlain with sparse grey pubescence, admixed with dark setae on anterolateral surfaces of mid and fore coxae, posterolateral surface of hind coxa; legs glossy black-brown with pale suffusion, tarsi paler in colour than other segments, numerous short dark setae on femora; wing bright orange, darker basally, venation orange; haltere stem orange, knob orange and brown; scutal chaetotaxy (pairs): np, 4; sa, 1; pa, 2; dc, 3; sc, 2.

Abdomen. Bulbous, tapering abruptly, glossy black-brown, covered with short dark setae; sternites overlain with silver pubescence; terminalia bright orange.

Male genitalia. Epandrium flat, trapezoidal, posterolateral corners pointed, covered with short setae (Fig. 2A); cerci rounded; tergite 8 emarginate medially, setae on posterior margin laterally (Fig. 2B); sternite 8 quadrangular (Fig. 2E); hypandrium triangular, partially fused to gonocoxites laterally; gonocoxite rounded, without medial atrium (Figs 2C-D), numerous large dark setae located posteroventrally; ventral lobe relatively small; gonocoxal apodeme narrow, much shorter than gonocoxite length; gonocoxal process present, narrow, almost equal in length to inner gonocoxal process; inner gonocoxal process spatulate apically; gonostylus with strong, medially directed setae; distiphallus straight, dorsal apodeme of parameral sheath ' $\mathrm{Y}$ '-shaped, well sclerotised (Figs $2 \mathrm{~F}-\mathrm{G}$ ); ventral apodeme of parameral sheath relatively short, forked; lateral ejaculatory apodeme narrow, band-like; ejaculatory apodeme, relatively large basally, laterally spatulate at anterior end.

Female. Body length: $8.0 \mathrm{~mm}$.

Similar to male except: Frons slightly wider than ocellar tubercle; shorter setae on head thorax and abdomen; scutum with short dark setae.

Female Genitalia. Anterior process of tergite 8 narrow; three spermathecae, spermathecal sac relatively large, trilobate, each with multiple lobes; furca well sclerotised, ring-like.

\section{Etymology}

The specific epithet is derived from the Latin: albus, white; and dorsum, dorsal, referring to the matte, white-grey pubescent covering of the scutum.

\section{Comments}

Eupsilocephala albodorsalis sp. nov. is similar to E. kroeberi, but is easily distinguished by the presence of extensive pale scutal pubescence. Males of this species have been observed drinking water at drying streams in south-eastern Queensland in late winter. 


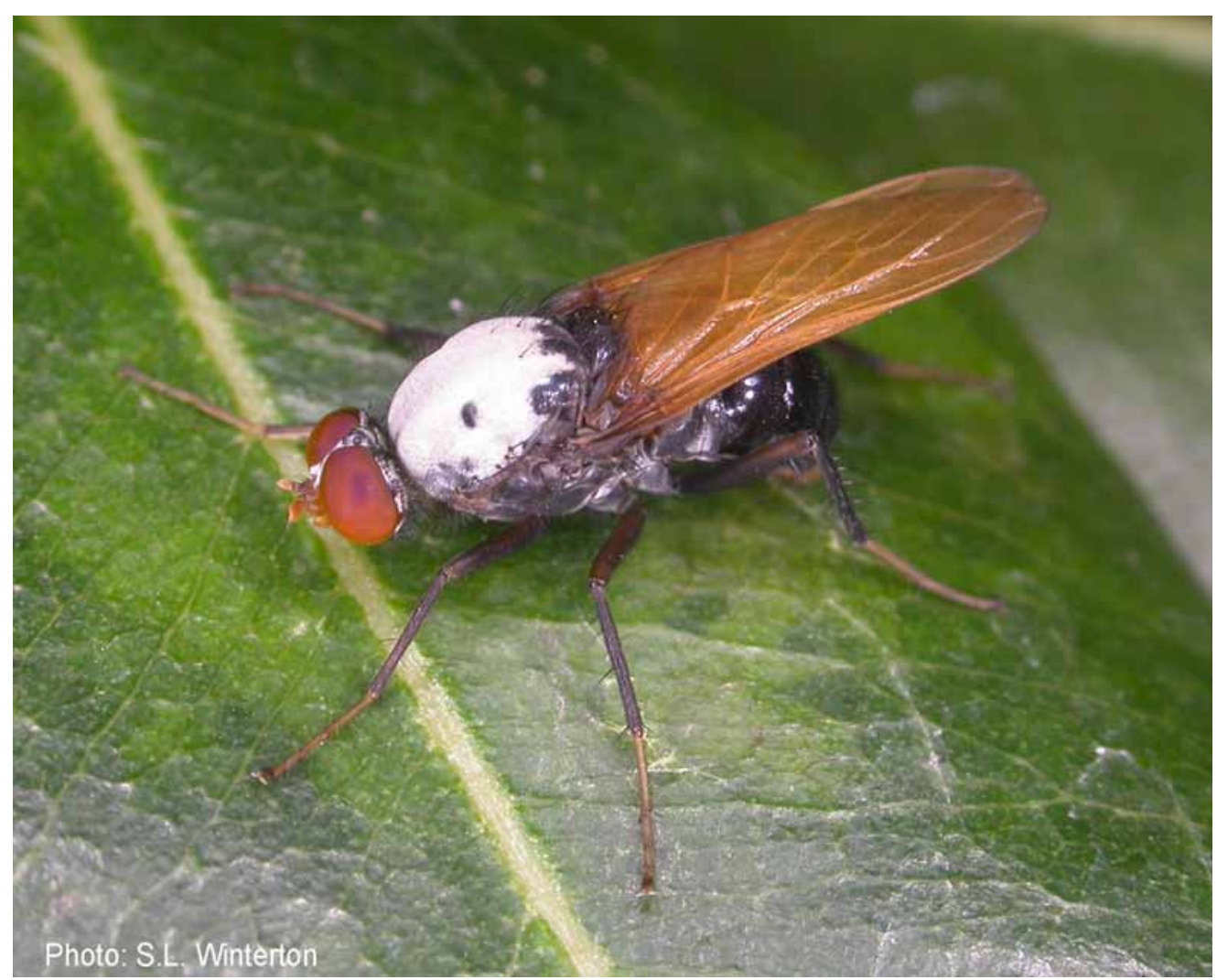

FIGURE 1. Eupsilocephala albodorsalis sp. nov., male. Body length= $7.0 \mathrm{~mm}$. Photo by Shaun L. Winterton.

\section{Eupsilocephala sulphurea sp. nov.}

Holotype Female, AUSTRALIA: QUEENSLAND: Tamborine Mountain, W.H. Davidson (MEI33876) (QMBA).

\section{Diagnosis}

Body glossy orange-brown, not metallic; wing with pale orange suffusion only; head and scutal macrosetae black.

\section{Description}

Female: Body length: $c a .7 .0 \mathrm{~mm}$.

Head. Frons slightly concave medially, width much wider than ocellar tubercle at narrowest point; head dark orange, overlain with sparse grey pubescence; eye ommatidia uniform size throughout eye; ocellar tubercle raised, black, overlain with sparse grey pubescence admixed with dark setae; occiput convex, dark orange, overlain with sparse 
silver pubescence, multiple rows of black postocular setae; gena orange, overlain with silver pubescence admixed with elongate setae; palp and labellum orange, covered with dark setae; antenna orange, darker apically, flagellum dark brown, overlain with sparse grey pubescence, antennal length shorter than head, scattered, dark setae on scape and pedicel.
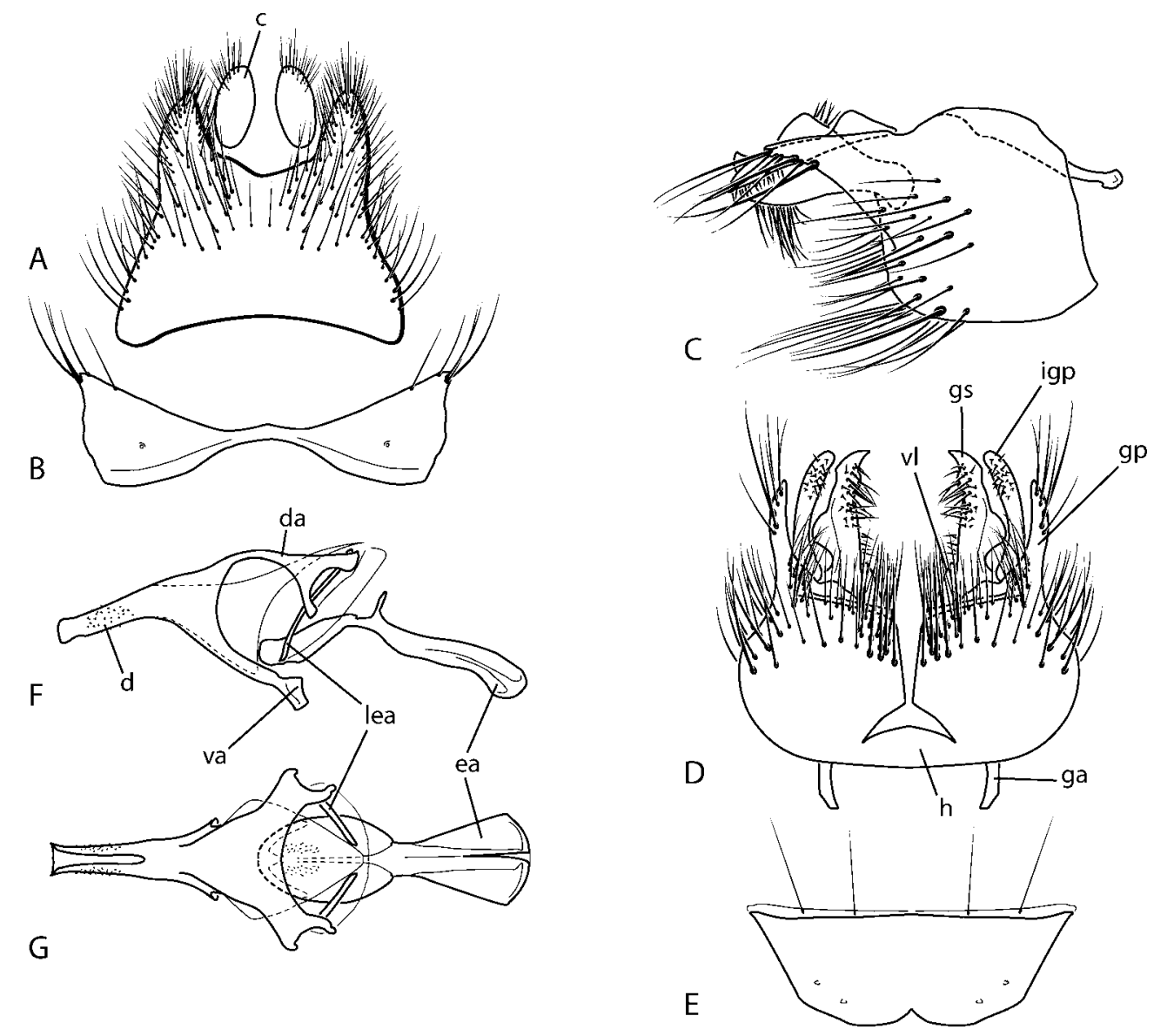

FIGURE 2. Eupsilocephala albodorsalis sp. nov., Male genitalia: A, epandrium, dorsal view; B, tergite 8, dorsal view; C, gonocoxites lateral view; D, same, ventral view; E, sternite 8, ventral view; F, aedeagus, lateral view; $\mathrm{G}$, same, dorsal view. Abbreviations: $c$, cercus; $d$, distiphallus; $d a$, dorsal apodeme of parameral sheath; $e a$, ejaculatory apodeme; $g a$, gonocoxal apodeme; $g p$, gonocoxal process; $g s$, gonostylus; $h$, hypandrium; igp, inner gonocoxal process; lea, lateral ejaculatory apodeme; $v a$, ventral apodeme of parameral sheath; $v l$, ventral lobe. Scale line $=0.5$ $\mathrm{mm}$.

Thorax. Thorax glossy orange-brown, scutum overlain with sparse grey pubescence, admixed with short dark setae, scutal macrosetae black, two black dorsocentral stripes along length of scutum; scutellum glossy orange; pleuron with elongate dark setae on 
proepisternum, anepisternum, katepisternum and katatergite; sparse grey-pubescence on meron, metanepisternum and posterior margin of katepisternum; coxae orange, overlain with sparse grey pubescence, admixed with dark setae on anterolateral surfaces of mid and fore coxae, lateral surface of hind coxa; legs brown, hind femur pale orange-brown; numerous short dark setae on femora; wing (damaged) pale orange; venation orange; haltere orange, knob pale; scutal chaetotaxy (pairs): np, 4; sa, 1; pa, 2; dc, 3; sc, 2.

Abdomen. Bulbous, tapering abruptly, glossy orange-brown, covered with short dark setae; terminalia dark.

Female Genitalia. Not dissected.

Male. Unknown.

\section{Etymology}

The specific epithet is derived from the Latin: sulphurea, yellow-orange; referring to the orange body colour.

\section{Comments}

Eupsilocephala sulphurea sp. nov. is the only orange coloured species in the genus and is smaller in body size to the other species. It is known only from a single, poorly preserved female specimen from Tamborine Mountain in south-eastern Queensland.

\section{Acknowledgements}

Thank you to Eric Fisher, Stephen Gaimari, and Martin Hauser for their comments on the draft manuscript. Thank you also to David Yeates and Christine Lambkin (ANIC) for help with the loan of specimens.

\section{References}

Hauser, M. \& Irwin, M.E. (2003) The Nearctic Genus Ammonaios Irwin and Lyneborg 1981 (Diptera: Therevidae). Annals of the Entomological Society of America, 96, 738-765.

Irwin, M.E. \& Lyneborg, L. (1981) Therevidae. Chapter 37, pages 513-523, In J.F. McAlpine, B.V. Peterson, G.E. Shewell, H.J. Teskey, J.R. Vockeroth, \& D.M. Wood (coords.), Manual of Nearctic Diptera, Volume 1. Monograph No. 27, Research Branch, Agriculture Canada.

Kampmeier, G.E., Irwin, M.E. \& Algmin, K. (2004) Mandala 5.3: A database system for systematics \& biodiversity studies. Diptera Data Dissemination Disk II (CD-ROM). North American Dipterists Society.

Kröber, O. (1912) Die Thereviden der indoaustralischen Region. (Dipt). [part]. Entomologische Mitteilungen, 1, 242-256.

Lambkin, C.L., Recsei, J.M. \& Yeates, D.K. (2005) Systematic revision of Johnmannia Irwin and Lyneborg (Diptera: Therevidae): atypical metallic stiletto flies from Australian mesic habitats. Zootaxa, 866, 1-28. 
Lyneborg, L. (1992) Therevidae (Insecta: Diptera). Fauna of New Zealand/ Ko te Aitanga Pepeke o Aotearoa 24, DSIR Plant Protection/ Te Wahanga Manaaki Tupu, Auckland, 139 pp.

Lyneborg, L. (2001) The Australian Stiletto-flies of the Anabarhynchus Genus-group (Diptera: Therevidae). Entomonograph vol. 13, Apollo Books, Steenstrup, Denmark. 256 pp.

Mann, J.S. (1928) Revisional notes on Australian Therevidae. Part 1. Australian Zoologist, 5, 151-194.

Mann, J.S. (1933) Revisional notes on Australian Therevidae. Part 3. Australian Zoologist, 7, 325-344.

McAlpine, J.F. (1981) Morphology and Terminology - Adults. In: J.F. McAlpine, B.V. Peterson , G.E. Shewell, H.J. Teskey, J.R. Vockeroth, D.M. Wood (coords.) Manual of Nearctic Diptera, Volume 1. Research Branch, Agriculture Canada, Ottawa, pp. 9-63.

Metz, M.A., Webb, D.W. \& Irwin, M.E. (2003) A review of the genus Psilocephala Zetterstedt (Diptera: Therevidae) with the description of four new genera. Studia Dipterologica, 10, 227-266.

Nichols, S.W. (ed.) (1989) The Torre-Bueno glossary of entomology: revised edition. New York Entomological Society. 840 pp.

Paramonov, S.J. (1950) Notes on Australian Diptera (I-V). III A note on two Australian therevids. Annals and Magazine of Natural History, 3, 525-529.

Walker, F. (1848) List of the specimens of dipterous insects in the collections of the British Museum. Part I. British Museum, London. 229 pp.

Winterton, S.L., Irwin, M.E. \& Yeates, D.K. (1999a) Systematics of Nanexila gen. nov. (Diptera: Therevidae) from Australia. Invertebrate Taxonomy, 13, 237-308.

Winterton S.L., Irwin, M.E. \& Yeates, D.K. (1999b) Phylogenetic revision of the Taenogera Kröber genus-group (Diptera: Therevidae), with descriptions of two new genera. Australian Journal of Entomology, 38, 274-290.

Winterton, S.L., Merritt D., O'Toole, A., Irwin M.E. \& Yeates D.K. (1999c) Morphology and histology of the spermathecal sac, a novel structure in the female reproductive system of Therevidae (Diptera: Asiloidea). International Journal of Insect Morphology and Embryology, 28, 273-279.

Winterton, S.L., Yang, L., Wiegmann, B.M. \& Yeates, D.K. (2001) Phylogenetic revision of Agapophytinae subf. n. (Diptera: Therevidae) based on molecular and morphological evidence. Systematic Entomology, 26, 173-211.

Yang L., Wiegmann B.M., Yeates D.K. \& Irwin M.E. (2000). Higher-level phylogeny of the Therevidae (Diptera: Insecta) based on $28 \mathrm{~S}$ ribosomal and elongation factor-1a gene sequences. Molecular Phylogenetics and Evolution, 15, 440-451. 